\title{
Expanding Scientific Knowledge Frontiers: Open repositories in Developing Countries Supported by NRENs
}

\author{
Marangaze Munhepe Mulhanga ${ }^{1}$, Solange Rito Lima ${ }^{1}$, Venâncio Massingue ${ }^{2}$, \\ and João Nuno Ferreira ${ }^{3}$ \\ 1 Centro Algoritmi, Universidade do Minho, Portugal \\ 2 Universidade Eduardo Mondlane, Moçambique \\ 3 Fundação para a Ciência e a Tecnologia, Portugal \\ Email: mmunhepe@di.uminho.pt,solange@di.uminho.pt, \\ venancio.massingue@uem.mz, ferreira@fccn.pt
}

\begin{abstract}
The current scenario of Internet operation has brought many challenges and opportunities to science as result of the evolution of technologies and network infrastructures, key enablers to information access at distinct levels. Regarding research and teaching, scientific Open Access (OA) repositories play a key role in the production, dissemination and sharing of knowledge. OA repositories improve the visibility, accessibility and availability of results from teaching and research activities, contributing to the knowledge society through the provision of scientific publications without restrictions.

Taking worldwide OA initiatives and the Portuguese experience as case study, this paper analyzes technical challenges and strategies for building open repositories supported by National Research and Education Networks (NRENs) in the African context. Considering Mozambique as the main target of this paper, the study of: (i) existing national and international initiatives; (ii) MoRENet - the Mozambique Research and Education Network; and (iii) SABER repository, will support the proposal of a set of directives and policies for the development and sustainability of a common OA platform for scientific and academic national production. We believe that this open repository will bring an undeniable added value for Mozambique knowledge growth, fostering the country development at both scientific and social levels.
\end{abstract}

\section{Introduction}

Scientific Open Access (OA) repositories aim to provide unrestricted access to academic and scientific literature resorting to information systems that store and give access to data. Therefore, an OA repository is a collection of documents in electronic format, freely available to users through the Internet. The debate on unrestricted access to academic and scientific literature has emerged mainly due to the limitations associated with the marketing of works published on scientific journals. Scientific journals are used as tools to disseminate research 
results in different fields of knowledge. The results of scientific work conducted by researchers, which are in most cases financed by funds or grants from the researcher institution, are submitted free of charge to scientific journals. Contrarily, the monopoly of commercial scientific publishers oblige the institutions libraries to buy the same publications, a fact which motivated the OA movement [1. As result, national and institutional self-archiving policies have been adopted, particularly in Europe and United States, as a way to encourage OA. Self-archiving means that authors deposit their scientific production in platforms or repositories, which will make them available publicly through the Internet. However, due to imposed restrictions, this process may incur in a 6 to 12 months latency, within which the documents are not available. In the case of research and education institutions, one of the easiest ways of self-archiving has been through OA repositories.

In this context, Portugal is seen as a success case due to the creation of the Portuguese Scientific Open Access Repository (Repositório Científico de Acesso Aberto de Portugal - RCAAP). This meta-repository is supported by Fundação para a Ciência e a Tecnologia - FCT (through Fundação para a Computação Cientifica Nacional (FCCN) unit), the national entity responsible for managing the National Research and Education Network (NREN), which provides highspeed connectivity and advanced services to academic and research institutions.

In the African context, there are still many challenges regarding the implementation and evolution of OA repositories. In the case of Mozambique, the national repository SABER, created in 2009, is the only repository in the country, however, most of the Mozambican institutions are not yet integrated. Regarding the infrastructural support, the Mozambique Research and Education Network (MoRENet) is the national NREN under deployment which is expected to bring connectivity and added-value services to the involved institutions.

Facing this scenario, this article aims at discussing the challenges and opportunities in the development and sustainability of OA repositories in the African context, focusing on Mozambique and its NREN. Having this purpose, it is important to study and define technical, organizational and funding aspects, taking into account: (i) national and international OA initiatives; (ii) national strategies for education, science and technology; (iii) the existence of open source software for the implementation of repositories; (iv) the alliance of NRENs in Eastern and Southern Africa (UbuntuNet Alliance); (v) the project AfricaConnect, supported by the European Commission, that aims to interconnect NRENs in sub-Saharan Africa.This article addresses these multiple components involved in the development of the OA national repository in Mozambique supported by MoRENet.

This article is organized as follows: Section 2 discusses OA initiatives, related promotion strategies and policies for OA self-archiving; Section 3 describes the Portuguese case study, involving its national repository; Section 4 presents the African context; Section 5 discusses the challenges and directives toward the evolution of OA repositories in Mozambique; and Section 6 presents the main conclusions of this work. 


\section{Open Access Initiatives and Strategies}

One of the first international OA initiatives with major impact was promoted in 2001 by the Open Society Institute (OSI) in Budapest. This event brought together researchers, higher education and research institutions leaders to discuss OA strategies. This meeting established the meaning and scope of OA, yielding one of the most important documents and initiatives spearheaded by the OA movement: the Budapest Open Access Initiative (BOAI). The defined strategies consider mainly journals and authors self-archives in OA repositories [2, [3, 4]. The Berlin Declaration, signed by representatives of several scientific institutions, was an important step in the realization of the OA movement strategy as it defines OA and encourages researchers and grant holders of scientific institutions to publish their works in accordance with the principles of OA [5] 6]. The action plan adopted by the world leaders of United Nation state members in the World Summit on the Information Society - WSIS, lay the foundations for an information society for all, reinforcing the importance of OA 7.

OA considers two types of documents: the final version of journal articles after peer reviewing (postprints) and unreviewed versions (preprints), in case of preliminary reports of new results. BOAI has defined two major pathways of OA: green OA proposes that authors through self-archiving deposit their publications in a OA repository, even if the article is published in a scientific journal; golden OA corresponds to the publication of OA scientific journals exempt from subscription or fees restricting the access to the published articles. These OA scientific journals present some similarities compared to traditional scientific journals, namely peer reviewing, editing and publication, differing in terms of access level, as signatures or other charges are not required.

At present, several types of repositories have been implemented: institutional; governmental; and thematic, adding up to 2516 repositories worldwide 8 . Table 1 illustrates the global landscape of OA repositories. As shown, the ranking is led by the European continent with 1169 repositories, followed by North America and Asia. Regarding the African continent, with a total of 86 repositories, South Africa is the forefront country with a total of $27 \mathrm{OA}$ repositories.

Regarding the implementation of repositories, there are several open source tools available, being EPrints and DSpace the most used. Currently, DSpace [9] has been the choice for implementing most repositories, about 1047 compared to 369 from EPrints [10]. One of the main advantages of DSpace is its simplicity, being able to run from simple to more sophisticated machines, as long as the server is capable of storing and processing data. The reduced cost on equipment is an advantage specially for institutions with limited financial resources and developing countries.

Open Access Policies - To encourage the practice of self-archiving, it is essential to define OA policies in two fronts: institutional and national levels. Different governments aim to break the monopoly of commercial scientific publishers, especially as regards scientific publication resulting from public funds. In 2007, the U.S. government took actions regarding the OA policy, resulting in a change in the biomedical and life sciences, with the adoption of a specific 
Table 1. Repositories in the World

\begin{tabular}{|c|c|c|c|}
\hline Region & \# Repositories & Top country/region & \# Repositories \\
\hline \hline Africa & 85 & South Africa & 27 \\
\hline Asia & 438 & India & 65 \\
\hline Australasia & 59 & Australia & 47 \\
\hline Central America & 12 & Costa Rica/El Salvador & $6 / 6$ \\
\hline North America & 518 & EUA & 430 \\
\hline South America & 216 & Brazil & 75 \\
\hline Caribe & 16 & Cuba & 17 \\
\hline Europe & 1169 & United Kingdom & 219 \\
\hline Oceania & 3 & Fiji & 2 \\
\hline
\end{tabular}

law for the National Institutes of Health (NIH), which requires all researchers funded by this institution to deposit their articles published in scientific journals in the PubMed Central repository. In early 2013, the U.S. government extended the action taken for NIH to all institutions in the country.

The European Union (EU), following the strategies pursued by U.S., has developed several projects under the Seventh Framework Programme (FP7) for the period 2007-2013, highlighting OpenAIRE and MedOAnet (for mediterranean countries) that are supported by the European Commission [11. Horizon 2020, the new European funding program for research and innovation, which will start in 2014, reinforces recommendations previously defined, extending them to the availability of data and scientific literature in OA.

\section{NRENs and OA: Portugal as a Case Study}

National Research and Education Networks - NRENs are supported by nonprofit organizations with the mission of providing advanced services to the research and higher education community. In $2010,62 \%$ of countries in the world have a NREN, and the recognized European model was followed in various regions of the world. The international connectivity between NRENs of the European continent is provided by GEANT, enabling the collaboration among the members [12, [13]. Regarding the Portuguese NREN, supported by FCT, the evolution of its network infrastructure has allowed the developing of projects to support research and teaching, being RCAAP of major importance.

\subsection{RCAAP}

RCAAP, the Portuguese scientific OA repository created in 2009, has as main objectives: to increase the visibility, accessibility, dissemination of results of academic activity and national scientific research; to integrate the country into a number of international initiatives facilitating the interoperability and interconnection with other research centers, organizations financing research and 
higher education institutions with OA repositories worldwide. RCAAP is a metarepository aggregating 35 institutional repositories and 5 journals, allowing free access to a vast number of scientific national publications. In 2010, to enhance the visibility of scientific contents in Portuguese idiom, a Luso-Brazilian memorandum was established, aggregating OA sources from Portugal and Brazil, and the annual CONFOA conference was created. Internationally, RCAAP also collaborates with European projects, namely OpenAIRE and MedOAnet. As a successful Portuguese initiative, the number of documents aggregated in RCAAP exceeds currently the 120 thousand.

Presently, RCAAP has available a new service: the Institutional Repositories Hosting Service (Serviço de Alojamento de Repositórios Institucionais - SARI). SARI is a cloud-based repository service for institutions that do not want to assure technical aspects related to the implementation of repositories, such as servers, connectivity, maintenance, backups, upgrades and monitoring. This service is provided centrally, and institutions only have to worry with administrative aspects. From the 35 repositories participant in RCAAP, 10 are aggregated and 25 are hosted in SARI. Another service associated with SARI is the common repository, available for institutions that do not have their own repository due to their small size or low publications volume. Later on, an institution taking part of the common repository may evolve for an hosted repository, according to RCAAP policies. These concepts are illustrated in Figure 1 .

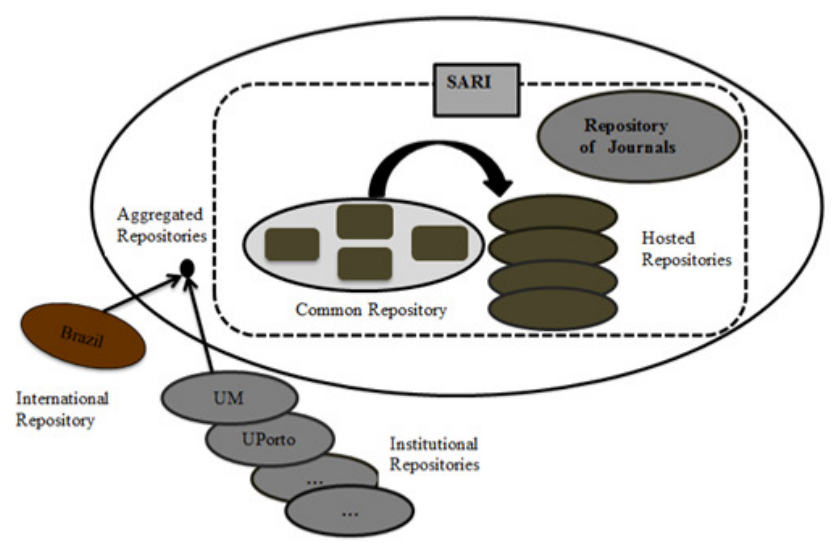

Fig. 1. National repository model - RCAAP

\section{Open Repositories in the African Context}

NRENs in Africa began to emerge about 10 years ago, especially in Eastern and Southern Africa. The high cost of broadband access and the lack of national 
and international infrastructures based on optical fiber are factors that have limited their development. Currently, with the deployment of intercontinental connections using optical fiber submarine cables and terrestrial fiber, broadband connectivity is expected to be available in most of African countries, although still very expensive compared to other world regions. The TENET in South Africa, the KENET in Kenya and the MAREN in Malawi are some success stories of NRENs operating in Africa.

Similarly to other continents, such as TERENA in Europe, the UbuntuNet Alliance is the association of African NRENs created in 2005 by 5 members established in Eastern and Southern Africa, MAREN (Malawi), MoRENet (Mozambique), KENET (Kenya), RwEdNet (Rwanda) and TENET (South Africa). To interconnect African NRENs with each other and with NRENs worldwide are the main goals of the alliance 14. Currently, it has 14 members.

AfricaConnect project is one of the examples of the international collaborative effort, supported by the European Commission. AfricaConnect wants to interconnect NRENs in sub-Saharan Africa to an international network of high capacity, fulfilling the goals of the UbuntuNet Alliance. The interconnection of the association members through GEANT will support research and education in Africa, through the integration into the global research community 11.

The Euro-Africa Cooperation Forum on ICT is the forum for cooperation on ICT between Africa and Europe resulting from a joint strategy adopted at the Lisbon Summit in 2007 [11. The forum aims to foster cooperation and sharing of experiences between the two continents.

The challenges of deploying OA repositories in Africa has been recently addressed in [15. Regarding the overall picture of scientific research, the author stresses that despite its ethnic and cultural diversity, and abundance of natural resources, Africa faces problems of post-colonial era: poverty; political instability; corruption; diseases and armed conflicts that undermine their growth.

Currently, Africa has 85 repositories 8 spread over only 19 of the 54 independent countries. As illustrated in Figure 2, South Africa is on top of the list with 27 repositories, followed by Kenya with 11, both members of UbuntuNet Alliance. From the five CPLP countries located in Africa, only Mozambique and Cape Verde take part of the list, being the repository "Knowledge Portal of Cape Verde" physically hosted at University of Minho (UM) in Portugal.

Scientific journals play a key role in the global knowledge society. The production of scientific OA journals in Africa is still scarce according to Directory of Open Access Journals (DOAJ) [16, as illustrated in Table 2 (UbuntuNet Alliance countries in grey). The "Open Access for Africa" event is a recent initiative promoting the discussion of issues related to scientific research, the quality of higher education and the role of OA journals in the African continent [17].

\section{Sharing Scientific Knowledge in Mozambique}

Mozambique, located in Southern Africa, is independent since 1975 and has Portuguese as its official language. With about 24 million people, $62 \%$ live in 


\begin{tabular}{|l|c|l|c|}
\hline \multicolumn{4}{|c|}{ Repositories in Africa } \\
\hline UbuntuNet Alliance Countries & Number & Other Countries & Number \\
\hline South Africa & 27 & Egypt, Nigeria & 7 \\
\hline Kenya & 11 & Zimbabwe & 4 \\
\hline Tanzania & 5 & Algeria, Ghana & 3 \\
\hline Namibia & 3 & Senegal, Tunisia & 2 \\
\hline Uganda & 2 & $\begin{array}{l}\text { Botswana, Cape } \\
\text { Verde, Cameroon, }\end{array}$ & 1 \\
\hline $\begin{array}{l}\text { Ethiopia, Mozambique } \\
\text { Lesotho }\end{array}$ & $\begin{array}{l}\text { Other 35 of 54 } \\
\text { African countries }\end{array}$ \\
\hline $\begin{array}{l}\text { Madagascar, Malawi, Congo } \\
\text { Semocratic Republic, Ruanda, } \\
\text { Somalia, Sudan, Zambia }\end{array}$ & 0 & $\begin{array}{l}\text { Total of Repositories } \\
\text { in Africa }\end{array}$ & $\mathbf{8 5}$ \\
\hline
\end{tabular}

Fig. 2. Distribution of open access repositories in Africa

Table 2. Distribution of journals in Africa

\begin{tabular}{|c|c|c|c|c|c|l|}
\hline Egypt & Tunisia & Morocco & Ethiopia & Algeria & Libya & $\begin{array}{l}\text { D.R. Congo, Ivory Cost, } \\
\text { Ghana, Burundi }\end{array}$ \\
\hline 459 & 9 & 7 & 6 & 5 & 2 & 1 each \\
\hline South Africa & Kenya & Uganda & Tanzania & Zambia & Madagascar & Ruanda \\
\hline 67 & 7 & 4 & 3 & 3 & 1 & 1 \\
\hline
\end{tabular}

rural areas, having an average lifespan of 50.7 years and $54 \%$ of Mozambicans live below the poverty line. The 2013 report of United Nations Development Program (UNDP) puts Mozambique in the 185th place, the third country with the worst Human Development Index (HDI).

Despite being one of the world's poorest countries, Mozambique is a steady growing country, and the International Monetary Fund (IMF) report of October 2013 [18 forecasts a growth of $8.5 \%$ in 2014. Currently, economic growth is the central concern of the country, especially for government and entrepreneurs, and the lack of skilled national workforce is a gap that must be solved. In this sense, the Mozambican government has endeavoured to create conditions for the country technological development, setting up several strategies, being one of the most relevant the Strategy for Science,Technology and Innovation.

\subsection{SABER - The National Repository}

The lack of scientific information is a reality in Mozambique and to reduce this limitation, the National Repository SABER was created in November 2009, to 
serve as a common platform for the involved 6 institutions: Judicial Training Centre; Higher Institute of Science and Technology of Mozambique; University Eduardo Mondlane (EMU); Pedagogical University; Polytechnic University; and University of St. Thomas of Mozambique. As reference, in 2011, Mozambique has 44 institutions of higher education, including public and private.

SABER holds scientific and academic documents produced in or related to Mozambique [19, being supported by the Ministry of Education and the World Bank for resource acquisition. The technical collaboration with UM in Portugal was revealed very helpful for setting up the repository, facing the experience of UM in this area. SABER is physically hosted at EMU, the oldest institution of higher education in the country, which is responsible for the technical support. The software adopted to implement the repository is Dspace. The administrative workflow tasks related to the deposit of documents in the repository is shared between the participant institutions. SABER has nearly 3,000 documents since its creation 8 .

SABER is the first repository in Mozambique, and the first in CPLP countries in Africa. Currently, it is evident the need to establish policies aiming at involving a larger number of institutions in SABER. In addition, the ministry of science and technology has shown interest in collaborating with resources and maintenance to support the evolution of SABER.

\subsection{MoreNET - Mozambique NREN}

MoRENet is the result of IT actions taken by Mozambican government. The adoption of IT policy in 2000 as a framework for the development of information society in the country, defines as main objectives: combating poverty and improving Mozambicans life conditions. One relevant aspect of this policy is ensuring the production and access to knowledge, in order to turn the country into a relevant and competitive partner in the global information society. The strategy plan for implementing this policy was adopted in 2002, and includes the implementation of MoRENet, coordinated by the Ministry of Science and Technology (MCT). Following this IT policy, in 2006 a new strategy was adopted the Strategy for Science, Technology and Innovation of Mozambique (ECTIM), with a horizon of 10 years, which aims to establish a framework conducive to the achievement of strategic objectives and programs that promote the development of an integrated system of science, technology and innovation.

As regards the implementation of MoRENet, there is still much work to do and there is a strong commitment and pressure to become operational in 2014 .

\subsection{Directions for the Evolution of a Common Open Access Platform}

From the discussion above, several points regarding OA may be stressed. OA Repositories are seen as one of the main resources used to deliver, store, and disseminate scientific and academic literature. The number of repositories has 
evolved to more than 2,500 in the world. The Berlin Declaration encouraged institutions in defining their OA policies based on the principles of self-archiving. The U.S. government has undertaken actions involving all institutions in the country based on the believe that scientific research output resulting from the support of public funds should be made available in OA repositories, as well as the scientific data resulting from it. The EU also recommended member states to develop national policies considering OA. All these measures represent the conscience of governments about the benefits of OA, creating policies and collaborative projects in this context.

The European NRENs model, where GEANT provides connectivity and collaboration among members, has been determinant to the success of NRENs in Europe. In Africa, with the deployment of intercontinental and local connections through fiber optic cables, the problem of broadband connectivity may be solved in most African countries, despite the high costs involved. AfricaConnect project represents an international collaborative effort to achieve the goals of the UbuntuNet Alliance regarding NRENs. In the case of Mozambique, the concretization of MoRENet will be an important step to offer connectivity and support services such as repository SABER.

RCAAP can be considered a successful national repository model supported by a NREN and may be followed by other countries. It also reveals the importance of government support through institutional collaboration (FCT and UM). SARI service provided by RCAAP is also a key aspect influencing the growth of repositories in the country. The creation of the Luso-Brazilian directory of repositories is a step forward in international collaboration.

Keeping in mind all these aspects, concrete actions fostering the evolution of SABER and the integration of distinct communities should be taken, considering: (i) journals and repositories, institutions and their departments, nongovernmental partners, national initiatives, publishers, professional associations and research groups; (ii) the evolution of the Mozambican scientific production may result in the implementation of new repositories hosted in MoRENet infrastructure and the emergence of new OA journals; (iii) apart from the technical issues of deploying repositories, the creation of institutional and national policies for self-archiving involving the government, MoRENet, SABER, and other partners, will enable the growth of the number of documents deposited in SABER and the number of existing repositories; (iv) regarding the institutions integrated into MoRENet, they should be involved in the NREN and OA projects to understand their needs for services, according to their location, since the country is vast and heterogenous regarding technology and social development.

\section{Conclusions}

Taking the relevance of OA repositories for expanding knowledge frontiers, this paper has focused on the challenges and strategies for developing open repositories in the African context. By studying OA initiatives and policies worldwide, and taking the Portuguese experience as case study, it was possible to identify 
the main difficulties and directions for the deployment and sustainability of OA repositories in Mozambique. NRENs play a key role in supporting research and teaching activities both at national an international levels, being an important vehicle for knowledge dissemination and growth. Therefore, we encourage the initial support of a common OA repository by the national NREN MoRENet.

Acknowledgments: The authors would like to thank UM documentation services and RCAAP by sharing expertise in OA field.

This work has been supported by FCT - Fundação para a Ciência e Tecnologia in the scope of the project: PEst-OE/EEI/UI0319/2014.

\section{References}

1. J. Willinsky, The Access Principle: The Case for Open Access to Research and Scholarship. Cambridge, Mass.: MIT Press, 2005.

2. W. Bailey, "The role of reference librarians in institutional repositories," Reference Services Review, vol. 33, pp. 259-267, 2005.

3. D. Kyriaki-Manessi, A. Koulouris, G. Giannakopoulos, and S. Zervos, "Exploratory research regarding faculty attitudes towards the institutional repository and self archiving," Procedia-Social and Behavioral Sciences, vol. 73, pp. 777-784, 2013.

4. J. X. et al., "A review of open access self-archiving mandate policies," Portal: Libraries and the Academy, vol. 12(1), pp. 85-102, 2012.

5. "Berlin declaration on open access to knowledge in the sciences and humanities," October 2003. [Online]. Available: http://openaccess.mpg.de/ 286432/Berlin-Declaration

6. S. Harnad, "The implementation of the berlin declaration on open access," D-lib Magazine, vol. 11, no. 3, March 2005.

7. The world summit on the information society (wsis). [Online]. Available: http://www.wsis.org

8. Directory of Open Access Repositories(OpenDOAR). Accessed 17 November 2013. [Online]. Available: http://www.opendoar.org

9. M. S. et al., "Dspace: An open source dynamic digital repository," D-Lib Magazine, vol. 9, no. 1, January 2003.

10. EPrints. [Online]. Available: http://www.eprints.org

11. European Commission (EU). [Online]. Available: http://ec.europa.eu

12. R. Janz and A. Kutanov, "The case of nrens in central asia," Central Asian Journal of Global Health, vol. 1, no. 1, 2012.

13. J. Dyer, "The case for nrens," TERENA, 2009. [Online]. Available: http: //www.terena.org

14. UbuntuNet Alliance. [Online]. Available: http://www.ubuntunet.net

15. W. E. Nwagwu, "Open access initiatives in africa - structure, incentives and disincentives," The Journal of Academic Librarianship, vol. 39, no. 1, pp. 3-10, 2013.

16. Directory of Open Access Journals (DOAJ). Accessed 22 November 2013. [Online]. Available: http://www.doaj.org

17. Open Access for Africa. [Online]. Available: http://www.biomedcentral.com/ developingcountries/events/openaccessafrica2010

18. (2013) World economic outlook (weo). International Monetary Fund. [Online]. Available: http://www.imf.org/external/pubs/ft/weo/2013/02

19. Multi-institutional Repository Saber. [Online]. Available: http://www.saber.ac.mz 